\title{
Design and Fabrication of the Lyophobic Slippery Surface and Its Application in Anti-icing
}

Nan Wang,,$^{\dagger}{ }^{\S}$ Dangsheng Xiong, ${ }^{* \dagger}, \S$ Yao Lu, ${ }^{\dagger}$ Sai Pan, ${ }^{\dagger}$ Kun Wang, ${ }^{\S}$ Yaling Deng, ${ }^{\S}$ and Yan $\mathrm{Shi}^{\S}$

${ }^{\dagger}$ School of Materials Science and Engineering, Nanjing University of Science and Technology, Nanjing 210094, Jiangsu, P. R. China

$\$$ Department of Chemistry, University College London, 20 Gordon Street, London, WC1H 0AJ, UK

$\S$ Jiangsu Key Laboratory of Advanced Micro/Nano Materials and Technologies, Nanjing 210094, Jiangsu, P. R. China

\begin{abstract}
A suspension that can be sprayed onto substrates was developed to form a superhydrophobic/oleophilic surface. Lyophobic slippery surfaces were prepared by infusing perfluorinated lubricants into the superhydrophobic coating to repel almost all liquids with low surface tension values, including hexane, kerosene and diesel oil, showing a transition between superoleophilicity and lyophobicity. In addition, the travelling speeds of liquids appeared to be negatively correlated with the kinematic viscosity. In the anti-icing tests, the droplet was pinned after contacting a $0^{\circ} \mathrm{C}$ textured superhydrophobic surface for a few seconds because of the meniscus caused by the condensation of atmospheric humidity; by contrast, on the lyophobic slippery surface, a water droplet could easily slide even at $-20^{\circ} \mathrm{C}$, demonstrating superior icing resistance.
\end{abstract}




\section{Introduction}

Super water repellency has been widely studied because of its various applications in self-cleaning, ${ }^{1,2}$ anti-icing, ${ }^{3,4}$ anti-corrosion, ${ }^{5-7}$ fluidic drag-reducing, ${ }^{8-10}$ oil/water separation, ${ }^{11,12}$ microfluidic devices, ${ }^{13,14}$ and even oil purification. ${ }^{15}$ Many methods for the preparation of superhydrophobic surfaces have been developed, including top-down methods (e.g., chemical etching on metal/Si substrates, ${ }^{16,17}$ or laser irradiation ${ }^{18,}{ }^{19}$ ), nano-polymer composites, ${ }^{20-23}$ and depositions. ${ }^{24-27} \mathrm{Ou}$ et al. prepared superhydrophobic surfaces via etching/oxidation followed by surface modification. ${ }^{28}$ Tesler et al. developed a self-cleaning coating on metallic surfaces that showed extremely high mechanical robustness. ${ }^{29}$ In our previous work, we developed a $\mathrm{SiO}_{2}$-NiO-UHMWPE (ultra-high-molecular-weight polyethylene)-based superhydrophobic coating that could be recycled and reused. ${ }^{15}$ The amphiphobic surfaces that exhibit repellency toward both water and oil have been a hot topic because of their prospective use in a broad range of oil transport and anti-scaling applications. Inspired by the Nepenthes pitcher plants, ${ }^{30}$ slippery-liquid-infused porous surface(s) (SLIPS) have attracted tremendous interest because of their repellency of liquids with surface tensions lower than that of water, such as hexane and diesel oil. These liquids can easily slide off SLIPS without any contamination. However, the key factors that control the travelling speed of a droplet on such SLIPS remain unclear.

With regard to the anti-icing properties of superhydrophobic surfaces, current methods mainly focus on minimizing the contact time; ${ }^{31}$ the water droplets bounce off the superhydrophobic surface at a temperature well below the water freezing point, thereby effectively preventing the icing process. In the aforementioned mentioned mechanism, the contact time between the water droplet and the cold substrate is very short (typically within 20 ms). However, whether the superhydrophobic surface would be icephobic if given a longer water 
contact time (longer than $1 \mathrm{~s}$ ) instead of a sudden impact is not known. In recent years, the anti-icing properties of superhydrophobic surfaces have been questioned; that is, the anti-icing efficiency is much lower in conditions of high atmospheric humidity, indicating that the superhydrophobic coatings are not always icephobic. ${ }^{32-34}$ Therefore, the development of a surface that could repel almost all liquids without being influenced by the condensation of air humidity is a desirable objective.

In this work, we fabricated a superhydrophobic surface by spraying a suspension consisting of $\mathrm{SiO}_{2}$ nanoparticles and polymethylmethacrylate (PMMA) onto substrates. A SLIPS was obtained through infusing perfluorinated lubricants onto the superhydrophobic surface, to repel water, milk, hexane, kerosene and diesel oil. The prepared SLIPS could still function at $-20^{\circ} \mathrm{C}$, suggesting remarkable anti-icing ability. Although a series of SLIPS studies of such surfaces have been previously reported, they have been mainly focused on the interactions with water, such as icing, ${ }^{35,36}$ water condensation, ${ }^{37}$ and improving the mobility of water on slippery surfaces. ${ }^{38}$ In this study, we focused on the dynamic behavior and sought to elucidate the factors that control the travelling speed of different liquids on lyophobic slippery surfaces.

\section{Experimental Section}

Materials. Perfluorotripentylamine (Fluorinert ${ }^{\mathrm{TM}}$ FC-70) and polymethylmethacrylate (PMMA, 99\%) were purchased from Aladdin Co., Ltd, China. Kerosene was purchased from Sinopec. All other chemicals were obtained from Sigma-Aldrich (analytical-grade reagents) and used as received. Deionized water was dyed with methylene blue and kerosene was dyed with Oil Red O to aid visualization.

Fabrication of fluorinated $\mathrm{SiO}_{2}$. First, $2 \mathrm{~mL}$ of ammonium hydroxide (25\%) was added to 40 
$\mathrm{mL}$ of ethanol, and the solution was stirred at $60^{\circ} \mathrm{C}$ for $30 \mathrm{~min}$. Second, $2 \mathrm{~mL}$ of tetraethyl orthosilicate (TEOS) was added dropwise, and the solution was further stirred for $1 \mathrm{~h}$, left to age under ambient conditions for $12 \mathrm{~h}$, and then dried. Finally, the $\mathrm{SiO}_{2}$ nanoparticles were soaked into $2 \mathrm{wt} \% 1 \mathrm{H}, 1 \mathrm{H}, 2 \mathrm{H}, 2 \mathrm{H}$-perfluorodecyltriethoxysilane $\left(\mathrm{C}_{10} \mathrm{~F}_{17} \mathrm{H}_{4} \mathrm{Si}\left(\mathrm{OCH}_{2}-\mathrm{CH}_{3}\right)_{3}\right.$, FAS-17) in hexane at $40^{\circ} \mathrm{C}$ for $3 \mathrm{~h}$, and were then cleaned with hexane and desiccated in a drying oven.

Fabrication of superhydrophobic and SLIPS. a) Superhydrophobic surface. PMMA, modified $\mathrm{SiO}_{2}$ and tetrahydrofuran (THF) were mixed at a mass ratio of $1: x: 100$ and stirred vigorously at ambient condition for over $2 \mathrm{~h}$ to form a uniform suspension. Then, $10 \mathrm{~mL}$ of the suspension was added into the spray gun (jet nozzle diameter $=0.8 \mathrm{~mm}$, XiaPai W-71/77, China) and sprayed (pressure $=300 \mathrm{kPa}$ ) onto the specimens that were then dried at $60^{\circ} \mathrm{C}$ for $2 \mathrm{~h}$. The values of $x$ were $0,1,3,5$, and 7 , and the corresponding coatings obtained by the suspensions were denoted as A1-A5 (Figure 1a).

b) SLIPS. FC-70 was infused into the A5 coating, with the lubricant spreading spontaneously. The lubricating layer was maintained at $0.02 \mathrm{~g} / \mathrm{cm}^{2}$.

Characterizations. Surface morphologies were observed using scanning electron microscope (Hitachi S4800) and a true color confocal microscope (Axio CSM 700). Surface wettability was measured using a contact angle measurement instrument (JC2000D, China) with $5 \mu \mathrm{L}$ of deionized water at ambient temperature. A high-speed camera (IDT Y4) was used to record the bouncing process of $5 \mu \mathrm{L}$ deionized water droplets at 1000 frames per second; the zoom lens (Navitar Zoom 6000) attached to the camera through an adapter (Navitar 2.0x) was used to magnify the area; the droplet fell from a height of $\sim 5.1 \mathrm{~cm}$, with a calculated impact velocity of $\sim 1 \mathrm{~m} / \mathrm{s}$. The lyophobic property was characterized by measuring the travelling speeds of hexane, kerosene, diesel oil, water and milk on a tilted SLIPS (tilting angle, $\sim 5^{\circ}$; droplet sizes, $\sim 50 \pm 0.2$ 
$\mu \mathrm{L})$. The reported data were obtained as the average of 6 measurements at different locations on the sample. The anti-icing test was carried out in a freezing chamber (RGDS-500, Surui Instruments Co., Ltd.).

\section{Results and Discussion}

Figure 1a shows the contact angles (CAs) and sliding angles (SAs) of the A1-A5 samples. Clearly, the hydrophobicity of the prepared coatings was positively related with the addition of $\mathrm{SiO}_{2}$; the coating exhibited superhydrophobicity $\left(\mathrm{CA}=156^{\circ}, \mathrm{SA}=5^{\circ}\right)$ when the mass ratio of $\mathrm{SiO}_{2} / \mathrm{PMMA}$ reached 7. Figure $1 \mathrm{~b}$ shows the bouncing process of a $5 \mu \mathrm{L}$ water droplet impacting A5: the droplet impacted $(\mathrm{t}=2 \mathrm{~ms})$, retracted $(\mathrm{t}=5 \mathrm{~ms})$, and bounced $(\mathrm{t}=7-10 \mathrm{~ms})$ without wetting the surface, suggesting superior water repellency. However, the surface showed high affinity toward hexane, kerosene, and diesel oil, as shown in Figure 1c-e. The organic liquids were absorbed into the surface asperities upon the contact moment, demonstrating a highly oleophilic nature. Furthermore, the milk on the surface showed a contact angle of $143^{\circ}$, smaller than that of water, because of the organic components of the milk. Figure 2 shows that different surface morphologies were obtained with increasing $\mathrm{SiO}_{2}$ content. The surface exhibited a highly textured morphology for A5 (Figure 2e), and nanoscale asperities could also be observed; meanwhile, many microscale asperities were observed on the 3D morphology, as shown in Figure 2f, with an $\mathrm{Rq}$ (root-mean-square roughness) of $21.83 \mu \mathrm{m}$ and an $\mathrm{Ra}$ (arithmetic average roughness) of $18.04 \mu \mathrm{m}$. Therefore, the A5 surface comprises micro-nano-hierarchical structures. Additionally, the $\mathrm{SiO}_{2}$-PMMA was a low-surface-free-energy coating because the $\mathrm{SiO}_{2}$ particles were modified with FAS-17 (see Experimental section) and the PMMA was intrinsically hydrophobic. The micro-nano-hierarchical structures and low surface free energy resulted in 
surface superhydrophobicity. ${ }^{39}$

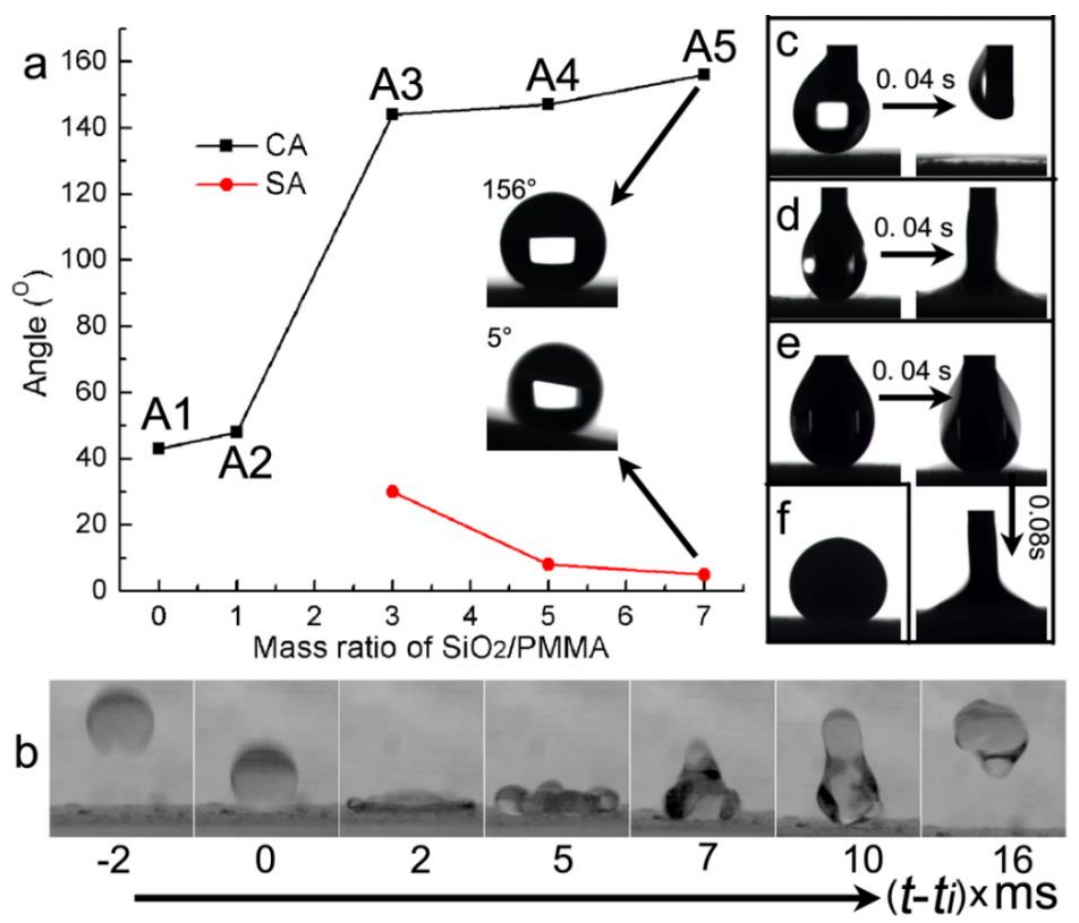

Figure 1. (a) Wettability (contact angle, CA, and sliding angle, SA) as a function of increasing $\mathrm{SiO}_{2}$ nanoparticle content. The A5 surface exhibited high water repellency $\left(\mathrm{CA}=156^{\circ}, \mathrm{SA}=5^{\circ}\right)$ when the $\mathrm{SiO}_{2} / \mathrm{PMMA}$ mass ratio reached 7:1. (b) Time-lapse optical images of water impacting, retracting, and bouncing off the A5 surface within $10 \mathrm{~ms}\left(t-t_{i}\right.$, where $t_{i}$ is the time of the moment of impact and $t$ is the time after the moment of impact). Droplet sizes, $5 \pm 0.2 \mu \mathrm{L}$. Impact velocity, $\sim 1 \mathrm{~m} / \mathrm{s}$. The A5 exhibited good affinity toward organic liquids such as (c) hexane, (d) kerosene, or (e) diesel oil; moreover, the surface showed less repellency toward (f) milk $\left(\mathrm{CA}=143^{\circ}\right)$ compared with water (a). 


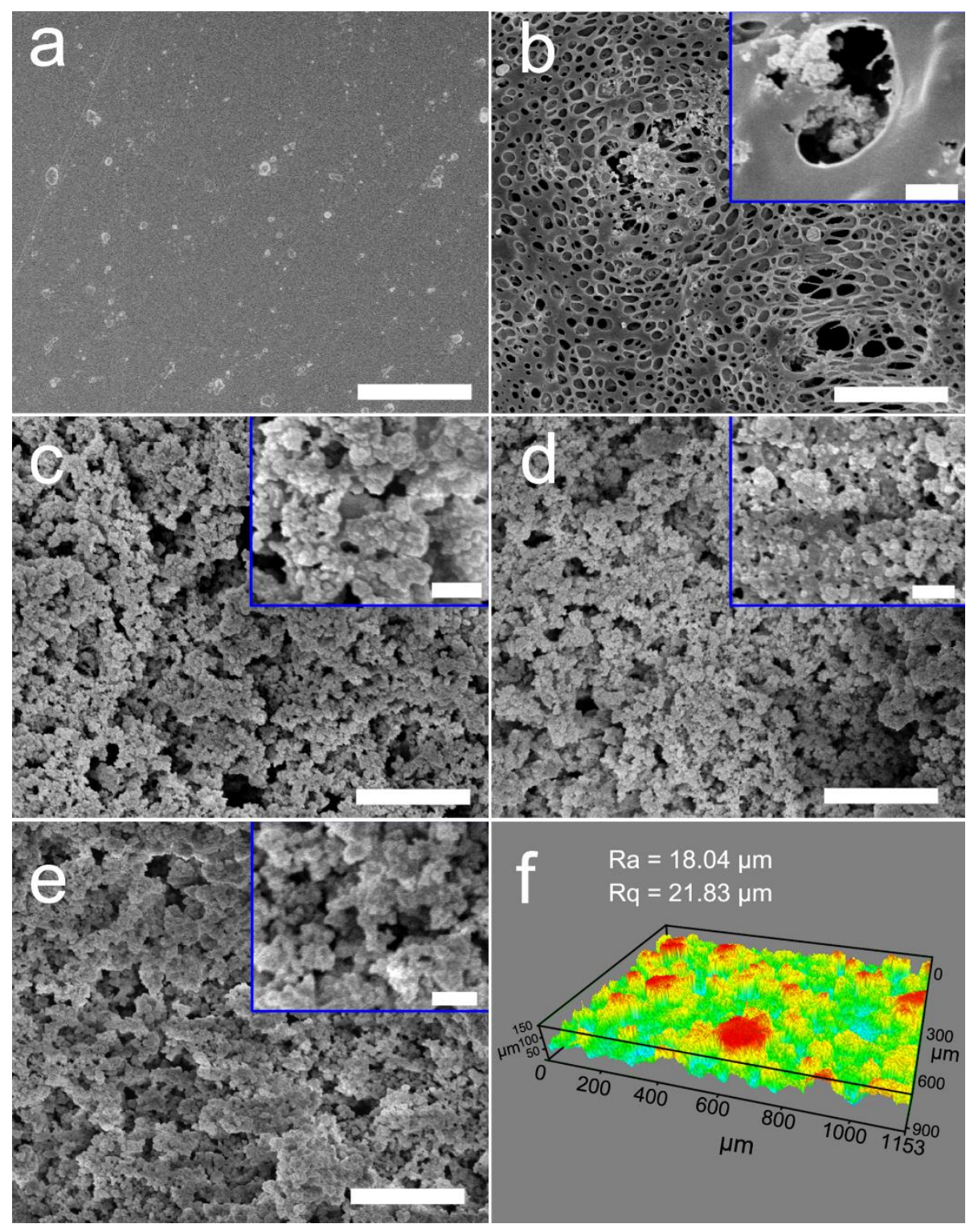

Figure 2. (a-e) SEM images of A1-A5, respectively. (f) 3D morphology of A5. Scale bars, $5 \mu$ m; inset scale bars, $500 \mathrm{~nm}$. 

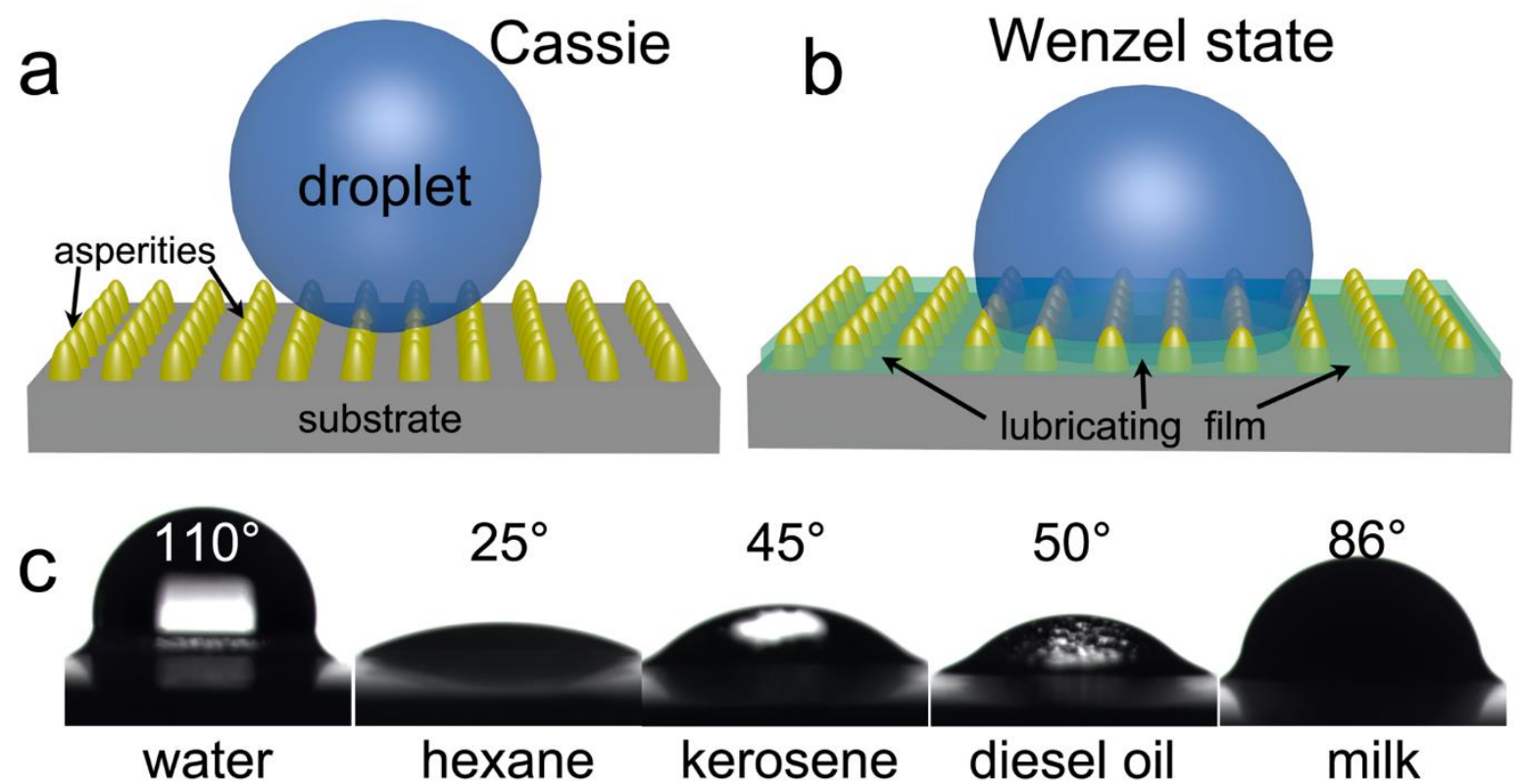

Figure 3. Wetting model of a water droplet on the A5 surface (a) before and (b) after the infusion of FC-70. (c) A $5 \mu \mathrm{L}$ droplet of water $(\gamma=72.0 \mathrm{mN} / \mathrm{m})$, hexane $(\gamma=18.6 \mathrm{mN} / \mathrm{m})$, kerosene $(\gamma=$ $24.5 \mathrm{mN} / \mathrm{m})$, diesel oil $(\gamma=26.8 \mathrm{mN} / \mathrm{m})$ and milk $(\gamma=41.5 \mathrm{mN} / \mathrm{m})$ on the SLIPS, where $\gamma$ is the surface tension of the testing liquids at $25^{\circ} \mathrm{C}$. The slippery surface showed repellency toward low-surface-tension liquids as well as toward water and milk, indicating a lyophobic property.

SLIPS have attracted intense attention in recent years because of their lyophobic nature that can resist almost all types of liquids. Here, we designed a slippery surface by infusing FC-70 into the roughness of the superhydrophobic A5 coating. Typically, the water droplet on a superhydrophobic surface remains in the Cassie state, ${ }^{40}$ where air pockets are created beneath the droplet, as shown in Figure 3a. For SLIPS, the encapsulated air is replaced by the FC-70 lubricant that soaks into the rough surface, ${ }^{30}$ as schematically shown in Figure $3 b$, and the water contact angle decreases from $156^{\circ}$ (Figure 1a) to $110^{\circ}$ (Figure 3c). Surprisingly, the SLIPS showed repellency toward the diesel oil, kerosene, and even hexane (Figure 3c); by contrast, the organic liquids were absorbed into the superhydrophobic surface upon contact, indicating a transition from superoleophilicity to lyophobicity. This behavior is a consequence of the extremely low surface tension of FC-70 $(\sim 17.1 \mathrm{mN} / \mathrm{m})$, which is immiscible with most of the 
investigated liquids, suggesting a lyophobic nature.

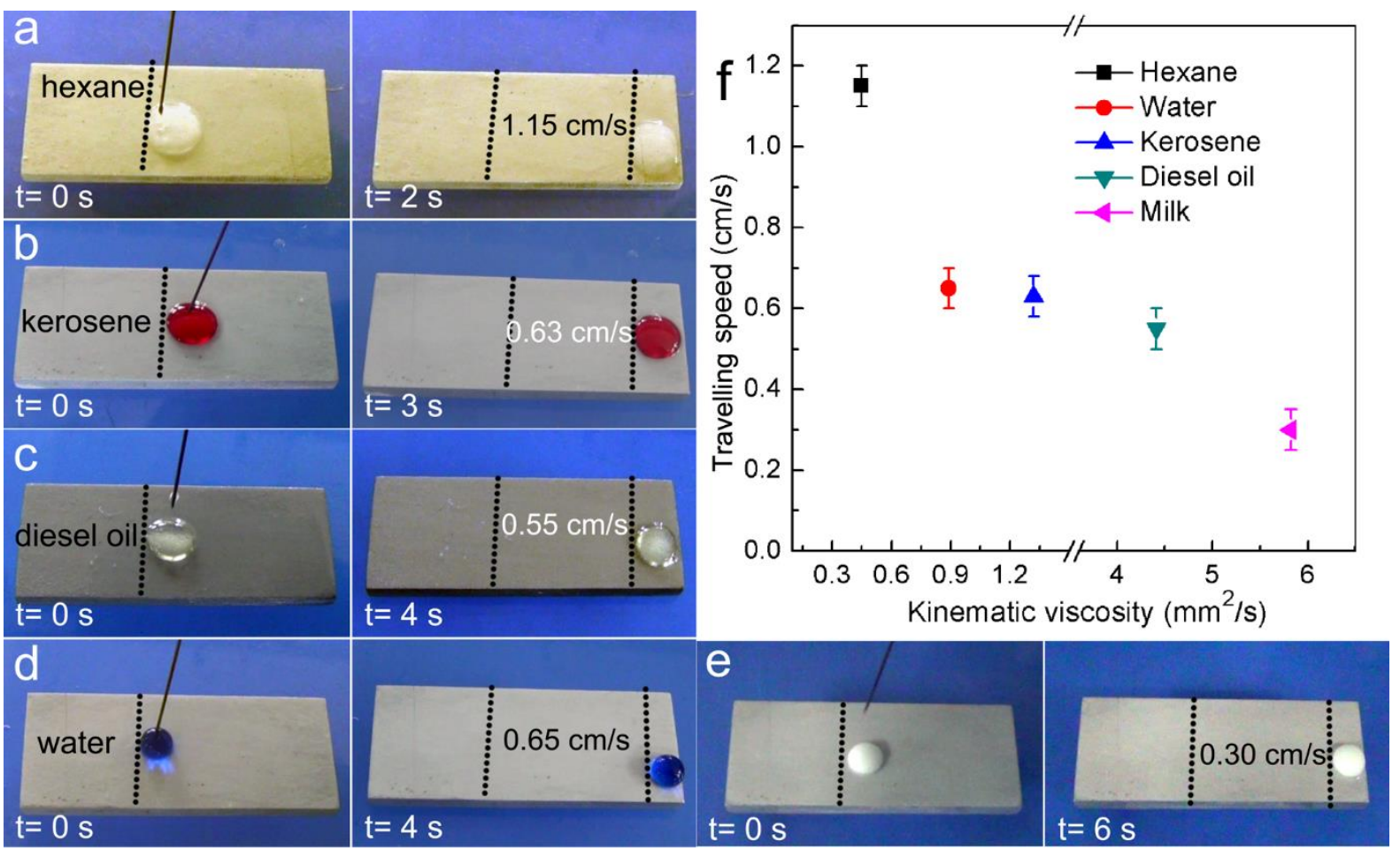

Figure 4. Lyophobic slippery surface. A $50 \mu \mathrm{L}$ droplet of (a) hexane $\left(\mathrm{v}=0.45 \mathrm{~mm}^{2} / \mathrm{s}, \mathrm{m}=\right.$ $0.032 \mathrm{~g}),(\mathbf{b})$ kerosene $\left(\mathrm{v}=1.32 \mathrm{~mm}^{2} / \mathrm{s}, \mathrm{m}=0.041 \mathrm{~g}\right),(\mathbf{c}) \operatorname{diesel}$ oil $\left(\mathrm{v}=4.41 \mathrm{~mm}^{2} / \mathrm{s}, \mathrm{m}=0.042 \mathrm{~g}\right)$, (d) water $\left(\mathrm{v}=0.89 \mathrm{~mm}^{2} / \mathrm{s}, \mathrm{m}=0.050 \mathrm{~g}\right)$ and (e) milk $\left(\mathrm{v}=5.82 \mathrm{~mm}^{2} / \mathrm{s}, \mathrm{m}=0.051 \mathrm{~g}\right)$ on the SLIPS at ambient temperature, where $\mathrm{v}$ and $\mathrm{m}$ are the kinematic viscosity and the mass of the liquid droplets at $25^{\circ} \mathrm{C}$, respectively. Sample tilting angle, $\sim 5^{\circ}$. Both the organic and water-based liquids could easily slide on the SLIPS. (f) The travelling velocity shows a negative correlation with the kinematic viscosity.

Although the static contact angles of water, hexane, kerosene, diesel oil and milk on the SLIPS were evaluated, as previously described (Figure 3c), characterizing the mobility of these droplets on the SLIPS using static contact angles is difficult. Here, we used the travelling speed of the droplets on the SLIPS to characterize the mobility of these liquids and the slipperiness of the SLIPS. Figure 4a-e and Movie S1 in the Supporting Information show the movement of 50 $\mu \mathrm{L}$ droplets on the FC-70-infused A5 surface: all the liquids easily slide on the surface, indicating 
that a lyophobic slippery surface was achieved. Furthermore, compared to milk, the low-surface-tension liquids exhibited smaller contact angles (Figure 3c) but higher travelling speeds (Figure 3e); in particular, the liquid with lowest surface tension, hexane $(\gamma=18.6 \mathrm{mN} / \mathrm{m})$, exhibited the highest mobility $(1.15 \mathrm{~cm} / \mathrm{s})$. Thus, the travelling speed was not determined by the contact angle. On the superhydrophobic surface, the travelling speed of a defined droplet is positively correlated with its self-weight. By contrast, on the prepared SLIPS, the liquids with similar weights, such as water $(\mathrm{m}=0.050 \mathrm{~g})$ and milk $(\mathrm{m}=0.051 \mathrm{~g})$, kerosene $(\mathrm{m}=0.041 \mathrm{~g})$ and diesel oil $(\mathrm{m}=0.042 \mathrm{~g})$, exhibited substantially different travelling speeds (Figure 4b-e). Meanwhile, the gravitational acceleration component along the inclined plane was the same for all of the liquids. Therefore, the acceleration and the velocity of these droplets were independent of their weights. We further analyzed the relationship between the mobility and kinematic viscosity of the droplets on the SLIPS, as shown in Figure 4f. The travelling speeds of different liquids exhibited a negative correlation with the kinematic viscosity. Thus, the slipperiness for the testing liquids on a SLIPS depended more on their kinematic viscosities than on their weights or contact angles. 


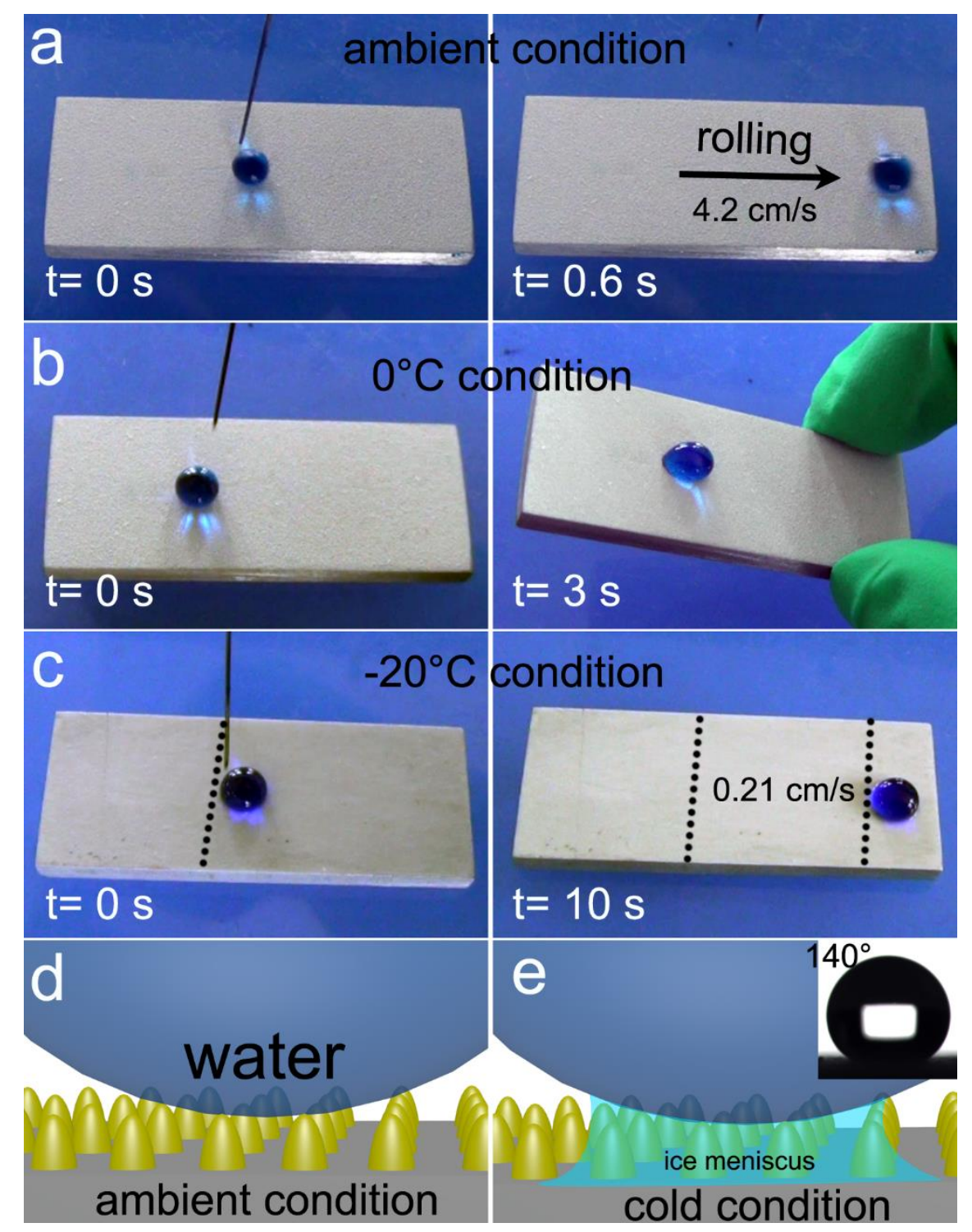

Figure 5. A $5 \mu \mathrm{L}$ water droplet on $\mathrm{A} 5$ at (a) ambient temperature and (b) $0{ }^{\circ} \mathrm{C}$. The droplets could roll off the surface within a short time and were pinned onto the surface after contacting the $0^{\circ} \mathrm{C}$ surface for a few seconds. (c) The droplet showed good mobility on SLIPS at $-20^{\circ} \mathrm{C}$. Sample tilting angle, $\sim 5^{\circ}$. (d and e) Schematics of the water droplet $\left(25^{\circ} \mathrm{C}\right)$ contacting the $\mathrm{A} 5$ in ambient and cold conditions (below $0^{\circ} \mathrm{C}$ ). In cold conditions, a water capillary bridge (meniscus) formed because of the condensation of atmospheric humidity and froze after contacting the cold substrate for a few seconds.

Anti-icing has been a hot topic in the field of superhydrophobicity. Most of the reported studies have mainly focused on the water impinging behavior: the droplet impacts, retracts, and bounces off such a surface within a short time before it freezes; Kreder et al. refer to this behavior 
as "minimized contact time." ${ }^{31}$ However, if the contact between the droplet and the cold surface is extended to a few seconds, would the superhydrophobic surface remain icephobic?

Figure 5a and b shows a $50 \mu \mathrm{L}$ water droplet on the superhydrophobic surface (A5) at different temperatures (for details, see Movie S2 in Supporting Information). The droplet rolled off the tilted $\left(\sim 5^{\circ}\right)$ surface easily within $0.6 \mathrm{~s}$ at ambient temperature; however, the droplet was pinned when it contacted the cold surface $\left(0^{\circ} \mathrm{C}\right)$ for a few seconds. Although the FAS molecules are not stable (long-term) in contact with water/ice according to Kulinich et al., ${ }^{41}$ the contact time was very short in our experiments; thus, the pinning was not due to the degradation of the hydrophobic properties. By comparison, the droplet showed good mobility on the lyophobic slippery surface at $-20^{\circ} \mathrm{C}$ (Figure $5 \mathrm{c}$, for details, see Movie S2). The pinning of the water droplet on the superhydrophobic surface at $0^{\circ} \mathrm{C}$ is mainly due to the water capillary bridge (meniscus) between the spherical droplet and the surface asperities. Normally, under ambient conditions, a large amount of air exists between the droplet and the superhydrophobic surface, as schematically illustrated in Figure 5d. Under low-temperature conditions (below $0^{\circ} \mathrm{C}$ ), when contact (between the droplet and the superhydrophobic surface) occurs in air, a water capillary bridge is formed via the condensation of atmospheric humidity, and would even freeze under cold conditions, as shown in Figure 5e. As reported previously, menisci exhibit a curvature and the pressure is reduced compared to the outside pressure, leading to a meniscus force between the droplet and substrate that is the main component of the adhesion force; ${ }^{42}$ meanwhile, the contact angle decreased from $156^{\circ}$ to $140^{\circ}$ because of the capillary bridge beneath the droplet. Thus, the superhydrophobic surface could not function in cold or extremely condensing conditions because the water capillary force (water meniscus) would form and then greatly increase the adhesion, resulting in a loss of water repellency. 
By contrast, a capillary bridge does not easily form on the lyophobic slippery surface at $-20^{\circ} \mathrm{C}$ because the air pockets beneath the droplet on the superhydrophobic surface are occupied by the lubricating fluids (FC-70, freezing point $-25^{\circ} \mathrm{C}$ ). During this process, a small amount of condensation water or ice could form; however, they are repelled by FC-70 and flow separately on the top of the lubricating layer because of the lower density of water/ice. Thus, the lyophobic slippery surface exhibits superior anti-icing ability.

\section{Conclusions}

In conclusion, we have designed a slippery liquid infused porous surface (SLIPS) via two steps: spraying $\mathrm{SiO}_{2}$-polymethylmethacrylate suspension onto substrates to form a superhydrophobic coating and infusing perfluorinated lubricant into the rough surface. The surface repelled hexane, kerosene, diesel oil, water and milk, demonstrating superior lyophobicity compared to superhydrophobic surfaces. The travelling velocity of the test droplet on the lyophobic slippery surface was observed to be negatively correlated with the kinematic viscosity. When a water droplet contacted the textured superhydrophobic surface at low temperatures (below $0^{\circ} \mathrm{C}$ ), a meniscus force formed between the water droplet and cold textured superhydrophobic surface, thus greatly increasing the adhesion force and deactivating the anti-icing capability of the superhydrophobic surface. However, the water droplet could easily slide on the lyophobic slippery surface even at $-20^{\circ} \mathrm{C}$, suggesting superior anti-icing properties compared to superhydrophobic surfaces. 


\section{ASSOCIATED CONTENT}

\section{Supporting Information}

Movie of different liquids on lyophobic slippery surface (Movie S1), movie of water droplets on superhydrophobic or lyophobic slippery surface in different temperatures (Movie S2). This material is available free of charge via the Internet at http://pubs.acs.org.

\section{AUTHOR INFORMATION}

\section{Corresponding Author}

*Email: xiongds@njust.edu.cnＰhone: (+86)025-84315325

\section{Notes}

The authors declare no competing financial interest.

\section{Acknowledgements}

This work has received financial support from the National Natural Science Foundation of China (NO. 51575278), Special fund for the transformation of scientific and technological achievements in Jiangsu Province (NO.BA2015054), and the Fundamental Research Funds for the Central Universities" (NO.30910612203), and project funding by the Priority Academic Program Development of Jiangsu Higher Education Institutions (PAPD).

\section{References}

(1) Blossey, R. Self-cleaning surfaces-virtual realities. Nat. Mater. 2003, 2, 301-306.

(2) Fürstner, R.; Barthlott, W.; Neinhuis, C.; Walzel, P. Wetting and self-cleaning properties of artificial superhydrophobic surfaces. Langmuir 2005, 21, 956-961.

(3)s, L.; Emelyanenko, A. M.; Korolev, V. V.; Pashinin, A. S. Effect of wettability on sessile drop 
freezing: When superhydrophobicity stimulates an extreme freezing delay. Langmuir 2014, 30, $1659-1668$.

(4) Wang, N.; Xiong, D.; Deng, Y.; Shi, Y.; Wang, K. Mechanically Robust Superhydrophobic Steel Surface with Anti-Icing, UV-Durability, and Corrosion Resistance Properties. ACS Appl. Mater. Interfaces 2015, 7, 6260-72.

(5) Liu, Y.; Li, S.; Zhang, J.; Liu, J.; Han, Z.; Ren, L. Corrosion inhibition of biomimetic super-hydrophobic electrodeposition coatings on copper substrate. Corros. Sci. 2015, 94, 190-196.

(6) Latthe, S. S.; Sudhagar, P.; Devadoss, A.; Kumar, A. M.; Liu, S.; Terashima, C.; Nakata, K.; Fujishima, A. A mechanically bendable superhydrophobic steel surface with self-cleaning and corrosion-resistant properties. J. Mater. Chem. A 2015, 3, 14263-14271.

(7) Wang, N.; Xiong, D. Superhydrophobic membranes on metal substrate and their corrosion protection in different corrosive media. Appl. Surf. Sci. 2014, 305, 603-608.

(8) Song, D.; Daniello, R. J.; Rothstein, J. P. Drag reduction using superhydrophobic sanded Teflon surfaces. Exp. Fluids 2014, 55, 1-8.

(9) Srinivasan, S.; Kleingartner, J. A.; Gilbert, J. B.; Cohen, R. E.; Milne, A. J.; McKinley, G. H. Sustainable Drag Reduction in Turbulent Taylor-Couette Flows by Depositing Sprayable Superhydrophobic Surfaces. Phys. Rev. Lett. 2015, 114, 014501.

(10)Kavalenka, M. N.; Vüllers, F.; Lischker, S.; Zeiger, C.; Hopf, A.; Röhrig, M.; Rapp, B. E.; Worgull, M.; Hölscher, H. Bioinspired air-retaining nanofur for drag reduction. ACS Appl. Mater. Interfaces 2015, 7, 10651-10655.

(11)Lee, C. H.; Johnson, N.; Drelich, J.; Yap, Y. K. The performance of superhydrophobic and superoleophilic carbon nanotube meshes in water-oil filtration. Carbon 2011, 49, 669-676. 
(12)Jayaramulu, K.; Datta, K. K. R.; Rösler, C.; Petr, M.; Otyepka, M.; Zboril, R.; Fischer, R. A. Biomimetic Superhydrophobic/Superoleophilic Highly Fluorinated Graphene Oxide and ZIF - 8 Composites for Oil-Water Separation. Angew. Chem. Int. Ed. 2016, 55, 1178-1182.

(13)Oliveira, N. M.; Neto, A. I.; Song, W.; Mano, J. F. Two-dimensional open microfluidic devices by tuning the wettability on patterned superhydrophobic polymeric surface. Appl. Phys. Express 2010, 3, 085205.

(14)Sousa, M. P.; Mano, J. F. Patterned superhydrophobic paper for microfluidic devices obtained by writing and printing. Cellulose 2013, 20, 2185-2190.

(15)Wang, N.; Lu, Y.; Xiong, D.; Carmalt, C. J.; Parkin, I. P. Designing durable and flexible superhydrophobic coatings and its application in oil purification. J. Mater. Chem. A 2016, 4, 4107-4116.

(16)Xiu, Y.; Liu, Y.; Hess, D. W.; Wong, C. P. Mechanically robust superhydrophobicity on hierarchically structured Si surfaces. Nanotechnology 2010, 21, 155705.

(17)Ou, J.; Hu, W.; Xue, M.; Wang, F.; Li, W. Superhydrophobic surfaces on light alloy substrates fabricated by a versatile process and their corrosion protection. ACS Appl. Mater. Interfaces 2013, 5, 3101-3107.

(18)Long, J.; Fan, P.; Gong, D.; Jiang, D.; Zhang, H.; Li, L.; Zhong, M. Superhydrophobic surfaces fabricated by femtosecond laser with tunable water adhesion: from lotus leaf to rose petal. ACS Appl. Mater. Interfaces 2015, 7, 9858-9865.

(19)Jagdheesh, R. Fabrication of a superhydrophobic $\mathrm{Al}_{2} \mathrm{O}_{3}$ surface using picosecond laser pulses. Langmuir 2014, 30, 12067-12073.

(20)Hsu, S. H.; Chang, Y. L.; Tu, Y. C.; Tsai, C. M.; Su, W. F. Omniphobic low moisture permeation transparent polyacrylate/silica nanocomposite. ACS Appl. Mater. Interfaces 2013, 5, 
2991-2998.

(21)Zhang, X.; Guo, Y.; Chen, H.; Zhu, W.; Zhang, P. A novel damage-tolerant superhydrophobic and superoleophilic material. J. Mater. Chem. A 2014, 2, 9002-9006.

(22)Guo, Z.; Zhou, F.; Hao, J.; Liu, W. Stable biomimetic super-hydrophobic engineering materials. J. Am. Chem. Soc. 2005, 127, 15670-15671.

(23)Jung, Y. C.; Bhushan, B. Mechanically durable carbon nanotube- composite hierarchical structures with superhydrophobicity, self-cleaning, and low-drag. ACS Nano 2009, 3, 4155-4163. (24)Sasmal, A. K.; Mondal, C.; Sinha, A. K.; Gauri, S. S.; Pal, J.; Aditya, T.; Ganguly, M.; Dey, S.; Pal, T. Fabrication of superhydrophobic copper surface on various substrates for roll-off, self-cleaning, and water/oil separation. ACS Appl. Mater. Interfaces 2014, 6, 22034-22043.

(25)Haghdoost, A.; Pitchumani, R. Fabricating superhydrophobic surfaces via a two-step electrodeposition technique. Langmuir 2014, 30, 4183-4191.

(26)Pham, V. H.; Dickerson, J. H. Superhydrophobic silanized melamine sponges as high efficiency oil absorbent materials. ACS Appl. Mater. Interfaces 2014, 6, 14181-14188.

(27)Zhou, H.; Wang, H.; Niu, H.; Gestos, A.; Wang, X.; Lin, T. Fluoroalkyl silane modified silicone rubber/nanoparticle composite: a super durable, robust superhydrophobic fabric coating. Adv. Mater. 2012, 24, 2409-2412.

(28)Ou, J.; Hu, W.; Liu, S.; Xue, M.; Wang, F.; Li, W. Superoleophobic textured copper surfaces fabricated by chemical etching/oxidation and surface fluorination. ACS Appl. Mater. Interfaces 2013, 5, 10035-10041.

(29)Tesler, A. B.; Kim, P.; Kolle, S.; Howell, C.; Ahanotu, O.; Aizenberg, J. Extremely durable biofouling-resistant metallic surfaces based on electrodeposited nanoporous tungstite films on steel. Nat. Commun. 2015, 6, 8649. 
(30)Wong, T. S.; Kang, S. H.; Tang, S. K.; Smythe, E. J.; Hatton, B. D.; Grinthal, A.; Aizenberg, J. Bioinspired self-repairing slippery surfaces with pressure-stable omniphobicity. Nature 2011, 477, 443-447.

(31)Kreder, M. J.; Alvarenga, J.; Kim, P.; Aizenberg, J. Design of anti-icing surfaces: smooth, textured or slippery? Nat. Rev. Mater. 2016, 1, 15003.

(32)Kulinich, S. A.; Farhadi, S.; Nose, K.; Du, X. W. Superhydrophobic surfaces: are they really ice-repellent? Langmuir 2011, 27, 25-29.

(33)Kim, P.; Wong, T. S.; Alvarenga, J.; Kreder, M. J.; Adorno-Martinez, W. E.; Aizenberg, J. Liquid-infused nanostructured surfaces with extreme anti-ice and anti-frost performance. $A C S$ Nano 2012, 6, 6569-6577.

(34) Stone, H. A. Ice-phobic surfaces that are wet. ACS Nano 2012, 6, 6536-6540.

(35)Subramanyam, S. B.; Rykaczewski, K.; Varanasi, K. K. Ice adhesion on lubricant-impregnated textured surfaces. Langmuir 2013, 29, 13414-13418.

(36)Zhu, L.; Xue, J.; Wang, Y.; Chen, Q.; Ding, J.; Wang, Q. Ice-phobic coatings based on silicon-oil-infused polydimethylsiloxane. ACS Appl. Mater. Interfaces 2013, 5, 4053-4062.

(37)Park, K. C.; Kim, P.; He, N.; Aizenberg, J. Condensation on Slippery Asymmetric Bumps. Nature 2015, 531, 78-82.

(38)Dai, X.; Stogin, B. B.; Yang, S.; Wong, T. S. Slippery Wenzel State. ACS Nano 2015, 9, 9260-9267.

(39) Lu, Y.; Sathasivam, S.; Song, J.; Crick, C. R.; Carmalt, C. J.; Parkin, I. P. Robust self-cleaning surfaces that function when exposed to either air or oil. Science 2015, 347, 1132-1135.

(40) Cassie, A. B. D.; Baxter, S. Wettability of porous surfaces. Trans. Faraday Soc. 1944, 40, 
546-551.

(41)Kulinich, S. A.; Honda, M.; Zhu, A. L.; Rozhin, A. G.; Du, X. W. The icephobic performance of alkyl-grafted aluminum surfaces. Soft Matter 2015, 11, 856-861.

(42)Nosonovsky, M.; Bhushan, B. Multiscale dissipative mechanisms and hierarchical surfaces:

friction, superhydrophobicity, and biomimetics, Springer Berlin Heidelberg, 2008; Chapter 5, pp $69-71$. 


\section{Table of Contents}

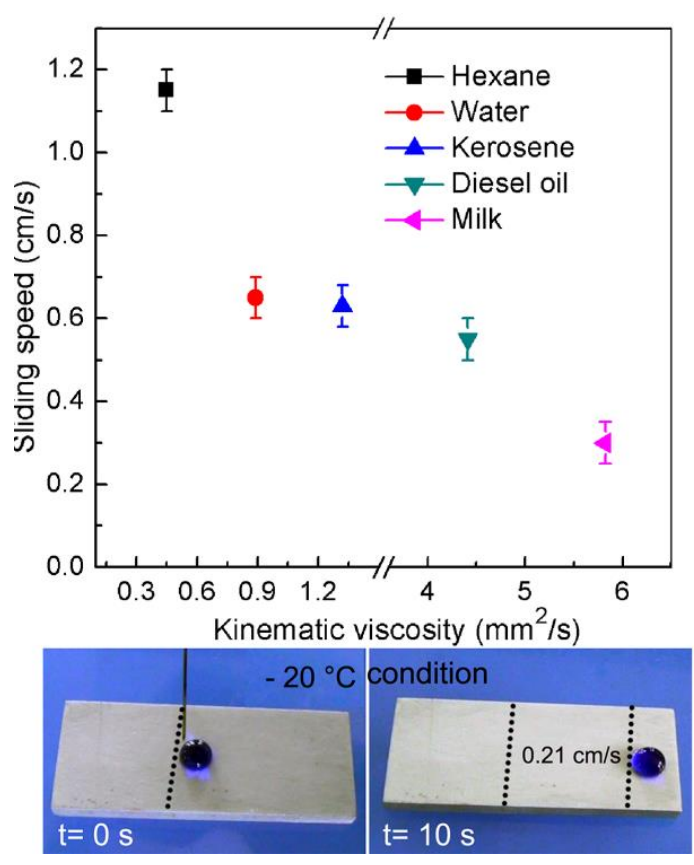

